\title{
ERRATUM
}

Robert Y. L. Zee - Nancy R. Cook Chung-Ah Kim

Arturo Fernandez-Cruz $\cdot$ Klaus Lindpaintner

\section{TP53 haplotype-based analysis and incidence of post-angioplasty restenosis}

Published online: 13 October 2004

(C) Springer-Verlag 2004

\section{Hum Genet (2004) 114:386-390}

In the Abstract section, the haplotypes (which appear twice in the abstract) should be 16bp--P72-G13494, and $16 b p+-P 72-A 13494$ (not R72).

The online version of the original article can be found at http:// dx.doi.org/10.1007/s00439-003-1080-8

R. Y. L. Zee $(\bowtie) \cdot$ N. R. Cook

Division of Preventive Medicine,

Brigham and Women's Hospital,

Harvard Medical School,

900 Commonwealth Avenue East,

Boston, MA 02215, USA

E-mail: rzee@rics.bwh.harvard.edu

Tel.: + 1-617-7328175

Fax: + 1-617-7839212

C.-A. Kim

Division of Endocrine-Hypertension,

Brigham and Women's Hospital,

Harvard Medical School, Boston,

Massachusetts, USA

A. Fernandez-Cruz

Hospital Universitario San Carlos,

Ciudad Universitaria, Madrid, Spain

K. Lindpaintner

F. Hoffmann-La Roche Ltd.,

Basel, Switzerland 